\title{
Research Article \\ Fuzzy Portfolio Selection Problem with Different Borrowing and Lending Rates
}

\author{
Wei Chen, Yiping Yang, and Hui Ma \\ School of Information, Capital University of Economics and Business, Beijing 100070, China \\ Correspondence should be addressed to Wei Chen, chenwei@cueb.edu.cn
}

Received 18 February 2011; Revised 27 April 2011; Accepted 29 May 2011

Academic Editor: Jyh Horng Chou

Copyright (C) 2011 Wei Chen et al. This is an open access article distributed under the Creative Commons Attribution License, which permits unrestricted use, distribution, and reproduction in any medium, provided the original work is properly cited.

\begin{abstract}
As we know, borrowing and lending risk-free assets arise extensively in the theory and practice of finance. However, little study has ever investigated them in fuzzy portfolio problem. In this paper, the returns of each assets are assumed to be fuzzy variables, then following the mean-variance approach, a new possibilistic portfolio selection model with different interest rates for borrowing and lending is proposed, in which the possibilistic semiabsolute deviation of the return is used to measure investment risk. The conventional probabilistic mean variance model can be transformed to a linear programming problem under possibility distributions. Finally, a numerical example is given to illustrate the modeling idea and the impact of borrowing and lending on optimal decision making.
\end{abstract}

\section{Introduction}

Portfolio selection is concerned with selecting a combination of securities among portfolios containing large numbers of securities to reach the investment goal. The portfolio selection model was first formulated by Markowitz [1], and it is called mean-variance model. The basic idea of mean-variance model is to measure the return as the expected value and risk as the variance from the expected value. Based on this model, there has been lots of theoretical and empirical work on portfolio selection problem. One of the hot research topics in this area is the introduction of alternative measures of risk. For example, Roy [2] proposed the so-called safety-first principle, that is to say, the investment objective is to minimize the ruin probability or maximize the chance of survival. Markowitz [3] used semivariance to measure risk so that only returns below expected value were measured as the risk. Konno and Yamazaki [4] proposed the MAD portfolio optimization model where risk is measured by mean absolute deviation. Speranza [5] proposed a portfolio model by using a linear combination of the mean semi-absolute deviations, that is, mean deviations below and above the portfolio rate of return, as the risk. Young [6] introduced a minimax model by minimizing the maximum loss over all past observation periods for a given level of return. Except these, other measures 
of risk, such as value at risk (VaR), conditional value at risk (CVaR), and expected shortfall are used for the portfolio problems (see [7-11]).

In the past, research has been undertaken on the assumption that future security returns can be correctly reflected by past performance and be represented by random variables. However, since the security market is so complex and the occurrence of new security is so quick, in many cases security returns cannot be accurately predicted by historical data. They are beset with ambiguity and vagueness. To deal with this problem, researchers have made use of fuzzy set theory proposed by Zadeh [12]. Assuming that the returns are fuzzy numbers, a great deal of work has been dedicated to studying portfolio selection problems. For example, Watada [13] considered portfolio selection problem by introducing the vague goals for expected return and risk. Tanaka and Guo [14] formulated portfolio selection models by quadratic programming, based on two kinds of possibility distributions. Inuiguchi and RamÍk [15] reviewed some fuzzy linear programming methods and techniques from a practical point of view and compared fuzzy mathematical programming approaches with those of stochastic programming. Tanaka et al. [16] also proposed two portfolio selection models based on fuzzy probabilities and possibility distributions, rather than conventional probability distributions as in Markowitz model. Inuiguchi and Tanino [17] proposed a new possibilistic programming approach based on the worst regret to the portfolio selection, considering how a model yields a distributive investment solution. Taking into account three criteria: return, risk, and liquidity, Arenas Parra et al. [18] formulated a fuzzy goal programming with fuzzy goals and fuzzy constraints. Carlsson et al. [19] introduced a possibilistic approach to selecting portfolios with highest utility score. Fang et al. [20] proposed a linear programming model for portfolio rebalancing with transaction costs, in which portfolio liquidity was also considered. Using Sharpe's single index model in a soft framework, Bilbao-Terol et al. [21] formulated a fuzzy compromise programming problem in order to solve portfolio selection problems. Vercher et al. [22] presented a fuzzy downside risk approach for managing portfolio problems in the framework of risk-return tradeoff using interval-valued expectations. Zhang et al. [23] proposed two kinds of portfolio selection models based on lower and upper possibilistic means and possibilistic variances, respectively, and introduced the notions of lower and upper possibilistic efficient portfolios. Ammar [24] solved the fuzzy portfolio optimization problem as a convex quadratic programming problem and provided an acceptable solution for it. Gupta et al. [25] applied multicriteria decision making via fuzzy mathematical programming to develop comprehensive portfolio selection models for the investors' pursuing either of the aggressive or conservative strategies. Chen [26] discussed some properties of weighted lower and upper possibilistic means and variances, and proposed two weighted possibilistic portfolio selection models with bounded constraint. Chen and Huang [27] introduced a basic portfolio selection model in which future return rates and future risks of mutual funds are represented by triangular fuzzy numbers. Li [28] defined a concept of skewness for fuzzy variable as the third central moment and then proposed three mean-variance-skewness models. Chen and Zhang [29] discussed the admissible portfolio selection problem with transaction costs and proposed an improved particle swarm optimization for the proposed model. Zhang et al. [30] proposed a possibilistic portfolio adjusting model with new added assets, in which transaction cost was considered. Bhattacharyya et al. [31] proposed a mean-variance-skewness model with transaction costs for portfolio selection with interval coefficients under the consideration of constraints on short- and long-term returns with transaction costs, liquidity, dividends, the number of assets in the portfolio, and the maximum and the minimum allowable capital invested in selected stocks. 
In the mature market, investors not only borrow money to expand their holdings of risky assets, but also lend to invest a portion of the portfolio in the risk-free assets such as short-term treasury securities. Recently, much attention has been focused in this area. For example, Tobin [32] extended the portfolio theory by showing that the investment decision could be separated into two phases: firstly, the selection of a unique optimum combination of risky assets and secondly, the allocation of funds between the unique optimum combination of risky assets and a single risk-free asset. Brennan [33] considered a model, where riskfree borrowing and lending are allowed, but at different interest rates. Bradfield and Raubenheimer [34] discussed the impact of restricted leverage, namely where investors are constrained either to hold funds in a risk-free asset (i.e., to lend) or to hold debt (i.e., to borrow), on optimal decision making in the usual mean-variance framework. Zhang et al. [35] extended traditional Markowitz model to case of different interest rates for borrowing and lending, and solve the proposed problems by the Kuhn-Tucker condition. More recently, Zhang and Wang [36] proposed the admissible efficient portfolio model when there exists the borrowing case, and formulated the analytic forms of the admissible efficient frontiers for two cases: the borrowing with an upper bound constraint, or without an upper bound constraint. In addition to considering differential borrowing and lending rates, Olson and Bley [37] focused on how the optimal portfolio changes for investors with different levels of risk tolerance.

Though a considerable number of research papers have been published for portfolio selection problem in fuzzy environment, there are little research on fuzzy portfolio selection problem under the consideration of different interest rates for borrowing and lending. In this paper, the focus of the research is to incorporate the possibility theory into a semi-absolute deviation portfolio selection model for investors' taking into account different interest rates for borrowing and lending in fuzzy environment. The rest of the paper is organized as follows. In Section 2, we propose a possibilistic mean semi-absolute deviation model for portfolio selection in which different interest rates for borrowing and lending are taken into account. In Section 3, a numerical example is presented to illustrate our proposed effective means and approaches. Finally, some concluding remarks are given in Section 4.

\section{Formulation of the Possibilistic Portfolio Model}

Let us give a brief description of Markowitz's mean-variance model. Consider an investment in $n$ risky assets over a certain period of time. Let $x_{j}$ be the proportion invested in asset $j$, and let $r_{j}$ be the return rate of asset $j, j=1,2, \ldots, n$. In order to describe conveniently, we set $\mathbf{x}=\left(x_{1}, x_{2}, \ldots, x_{n}\right)^{\prime}, \mathbf{r}=\left(r_{1}, r_{2}, \ldots, r_{n}\right)^{\prime}$, and $\mathbf{e}=(1,1, \ldots, 1)^{\prime}$. In usual mean-variance models, $r_{j}$ is regraded as a random variable, then the return associated with the portfolio $\mathbf{x}=$ $\left(x_{1}, x_{2}, \ldots, x_{n}\right)^{\prime}$ is given by $r=\sum_{j=1}^{n} x_{j} r_{j}=\mathbf{r}^{\prime} \mathbf{x}$. The expected return and variance of $r$ are given by $E(r)=\overline{\mathbf{r}}^{\prime} \mathbf{x}$, and $D(r)=\mathbf{x}^{\prime} \mathbf{V} \mathbf{x}$, where $\overline{\mathbf{r}}=\left(\bar{r}_{1}, \bar{r}_{2}, \ldots, \bar{r}_{n}\right)^{\prime}$ and $\mathbf{V}=\left(\sigma_{i j}\right)_{n \times n}$ are the expected return vector and the covariance matrix of expected returns, respectively. Thus, Markowitz's mean-variance model can be described by the following quadratic programming:

$$
\begin{array}{cl}
\min & \mathbf{x}^{\prime} \mathbf{V} \mathbf{x} \\
\text { s.t. } & \overline{\mathbf{r}}^{\prime} \mathbf{x}=\mu, \\
& \mathbf{e}^{\prime} \mathbf{x}=1, \\
& \mathbf{x} \geq 0,
\end{array}
$$

where $\mu$ is a required return of portfolio. 
However, the original result of Markowitz was derived in a discrete time, frictionless economy with the same interest rates for borrowing and lending. In reality, investors may be charged a higher interest rate for borrowing money than the interest rate for saving money. Even though many research works assume the same risk-free interest rate for borrowing and lending, the discrepancy between borrowing and lending is crucial for the operations of financial institutions.

In what follows we assume there are $n+1$ assets: $n$ risky assets and 1 risk-free asset with different interest rates for borrowing and lending. In addition, we assume the investor is charged a higher interest rate for borrowing than the interest rate for lending, that is, $r_{b} \geq r_{l}$. Therefore, the expected return rate on portfolio $\left(x_{1}, x_{2}, \ldots, x_{n}\right)$ is

$$
\mathbf{E}\left(\sum_{j=1}^{n} r_{j} x_{j}\right)+\left(1-\sum_{j=1}^{n} x_{j}\right) r(x)=\overline{\mathbf{r}}^{\prime} \mathbf{x}+\left(1-\mathbf{e}^{\prime} \mathbf{x}\right) r(x)
$$

where

$$
r(x)= \begin{cases}r_{l}, & \text { if } 1-\mathbf{e}^{\prime} \mathbf{x} \geq 0 \\ r_{b}, & \text { if } 1-\mathbf{e}^{\prime} \mathbf{x}<0\end{cases}
$$

It should be noted that if $1-\mathbf{e}^{\prime} \mathbf{x} \geq 0$, the investors short sell the portfolio of $n$ risky assets and invest (lend) the proceeds in the risk-free asset, then $r(x)=r_{l}$. If $1-\mathbf{e}^{\prime} \mathbf{x}<0$, the investors long sell the portfolio of $n$ risky assets and short sell (borrow) the proceeds in the risk-free asset, then $r(x)=r_{b}$.

Moreover, it is known that very high weighting in one asset will cause the investor to suffer from larger risk. Therefore, the upper bounds of each asset would be useful for the investor to select portfolios in reality.

Based on the above discussion, we assume that the objective of the investor is to choose a new optimal portfolio that minimizes the risk of the portfolio subject to some constraints on the expected return of the portfolio and asset holdings by adjusting the existing portfolio. Thus, the portfolio problem can be formulated as follows:

$$
\begin{array}{ll}
\min & \mathbf{x}^{\prime} \mathbf{V x} \\
\text { s.t. } & \overline{\mathbf{r}}^{\prime} \mathbf{x}+\left(1-\mathbf{e}^{\prime} \mathbf{x}\right) r(x) \geq \mu \\
& 0 \leq x_{j} \leq u_{j}, \quad j=1,2, \ldots, n
\end{array}
$$

Obviously, the optimal solution of model (2.4) depends on the accuracy of the expected return and the covariance matrix. It is wellknown that the financial market is affected by many nonprobabilistic factors. In a fuzzy uncertain economic environment, the future states of returns and risks of risky assets cannot be predicted accurately. However, in many important cases, the estimation of the possibility distributions of return rates on assets may be easier than the probability distributions. Moreover, by using fuzzy approaches, it is better to handle the vagueness and ambiguity in the investment environment and the investors' subjective opinions can be better integrated. Therefore, it is useful and meaningful to discuss the portfolio problem under the assumption that the returns of the assets are fuzzy numbers. 
Similar to the possibilistic approach introduced by Carlsson et al. [19] and Vercher et al. [22], fuzzy return rates are denoted as trapezoidal fuzzy numbers. Trapezoidal possibilistic distribution is only considered because it can easily be generalized to the case of possibility distribution of type LR. In this study, we also regard trapezoidal possibility distribution as the possibility distribution of the return rates.

Let $r_{j}$ be a trapezoidal fuzzy number with tolerance interval $\left[a_{j}, b_{j}\right]$, left width $\alpha_{j}$, and right width $\beta_{j}, j=1,2, \ldots, n$, that is, $r_{j}=\left(a_{j}, b_{j}, \alpha_{j}, \beta_{j}\right) . r_{j}$ can be described with the following membership function:

$$
r_{j}(t)= \begin{cases}1-\frac{a_{j}-t}{\alpha_{j}}, & \text { if } a_{j}-\alpha_{j} \leq t \leq a_{j} \\ 1, & \text { if } a_{j} \leq t \leq b_{j} \\ 1-\frac{t-b_{j}}{\beta_{j}}, & \text { if } b_{j} \leq t \leq b_{j}+\beta_{j} \\ 0, & \text { otherwise. }\end{cases}
$$

Then, a $\gamma$-level sets of $r_{j}$ can be computed as

$$
\left[r_{j}\right]^{\gamma}=\left[a_{j}-(1-\gamma) \alpha_{j}, b_{j}+(1-\gamma) \beta_{j}\right], \quad \forall \gamma \in[0,1]
$$

Based on [38], we know that the sum of independent trapezoidal fuzzy variables $\xi=$ $\left(a_{1}, a_{2}, a_{3}, a_{4}\right)$ and $\eta=\left(b_{1}, b_{2}, b_{3}, b_{4}\right)$ is also a trapezoidal fuzzy variable, that is, $\xi+\eta=$ $\left(a_{1}+b_{1}, a_{2}+b_{2}, a_{3}+b_{3}, a_{4}+b_{4}\right)$. Moreover, the product of a trapezoidal fuzzy variable $\xi=$ $\left(a_{1}, a_{2}, a_{3}, a_{4}\right)$ and a scalar number $\lambda$ is also a trapezoidal fuzzy variable, that is,

$$
\lambda \cdot \xi= \begin{cases}\left(\lambda a_{1}, \lambda a_{2}, \lambda a_{3}, \lambda a_{4}\right), & \text { if } \lambda \geq 0 \\ \left(\lambda a_{4}, \lambda a_{3}, \lambda a_{2}, \lambda a_{1}\right), & \text { if } \lambda<0 .\end{cases}
$$

Therefore, for any real numbers $x_{j} \geq 0, j=1,2, \ldots, n$, the total fuzzy return on a portfolio $P(x)=\left(x_{1}, x_{2}, \ldots, x_{n}\right)$ is

$$
\begin{aligned}
P & =\sum_{j=1}^{n} r_{j} x_{j} \\
& =\left(\sum_{j=1}^{n} a_{j} x_{j}, \sum_{j=1}^{n} b_{j} x_{j}, \sum_{j=1}^{n} \alpha_{j} x_{j}, \sum_{j=1}^{n} \beta_{j} x_{j}\right) \\
& =\left(P_{l}(x), P_{u}(x), C(x), D(x)\right),
\end{aligned}
$$

which is also a trapezoidal fuzzy number. 
Carlsson and Fullér [39] introduced the lower and upper possibilistic mean values of fuzzy number $A$ with $\gamma$-level set $[A]^{\gamma}=\left[a_{1}(\gamma), a_{2}(\gamma)\right](\gamma>0)$ as

$$
\begin{aligned}
& M_{*}(A)=2 \int_{0}^{1} r a_{1}(\gamma) d \gamma \\
& M^{*}(A)=2 \int_{0}^{1} r a_{2}(\gamma) d \gamma .
\end{aligned}
$$

Furthermore, Carlsson and Fullér [39] defined the interval-valued, and crisp possibilistic mean values of fuzzy number $A$ as:

$$
\begin{aligned}
& M(A)=\left[M_{*}(A), M^{*}(A)\right], \\
& \bar{M}(A)=\frac{M_{*}(A)+M^{*}(A)}{2} .
\end{aligned}
$$

According to the above definitions, we easily obtain the lower and upper possibilistic means, the interval-valued and crisp possibilistic mean values of the total fuzzy return as follows:

$$
\begin{gathered}
M_{*}(P)=2 \int_{0}^{1} \gamma\left(P_{l}(x)-C(x)(1-\gamma)\right) d \gamma=P_{l}(x)-\frac{1}{3} C(x), \\
M^{*}(P)=2 \int_{0}^{1} \gamma\left(P_{u}(x)+D(x)(1-\gamma)\right) d \gamma=P_{u}(x)+\frac{1}{3} D(x), \\
M(P)=\left[P_{l}(x)-\frac{1}{3} C(x), P_{u}(x)+\frac{1}{3} D(x)\right], \\
\bar{M}(P)=\frac{1}{2}\left(P_{l}(x)+P_{u}(x)\right)-\frac{1}{3}(C(x)-D(x)) .
\end{gathered}
$$

The following theorem can be found in [22].

Theorem 2.1. Let $r_{j}=\left(a_{j}, b_{j}, \alpha_{j}, \beta_{j}\right)$ be $n$ trapezoidal return of asset $j, j=1, \ldots, n$, and let $P=$ $\left(P_{l}(x), P_{u}(x), C(x), D(x)\right)$ be the total return of the portfolio $P(x)$, then

(a) $\max \{0, M(P)-P\}=\left(0, P_{u}(x)-P_{l}(x)+D(x) / 3,0, C(x)\right)$,

(b) $\omega(P)=M(\max \{0, M(P)-P\})=\left[0, P_{u}(x)-P_{l}(x)+(C(x)+D(x)) / 3\right]$.

In this paper, we will use possibilistic semi-absolute deviation, instead of the possibilistic variance employed by Carlsson et al. [19], to formulate possibilistic portfolio selection model. The semi-absolute deviation based on the probabilistic theory can be described as [5]

$$
E\left(\left|\min \left\{0, \sum_{j=1}^{n} r_{j} x_{j}-E\left(\sum_{j=1}^{n} r_{j} x_{j}\right)\right\}\right|\right)=E\left(\max \left\{0, E\left(\sum_{j=1}^{n} r_{j} x_{j}\right)-\sum_{j=1}^{n} r_{j} x_{j}\right\}\right) .
$$


Next, we evaluate the possibilistic mean absolute semi-deviation with respect to the total fuzzy return. Therefore, the possibilistic semi-absolute deviation can be defined as

$$
\omega(P)=M(\max \{0, M(P)-P\})
$$

Based on the Theorem 2.1, the interval-valued possibilistic semi-absolute deviation is represented as follows:

$$
\omega(P)=\left[0, P_{u}(x)-P_{l}(x)+\frac{(C(x)+D(x))}{3}\right] .
$$

Furthermore, we can obtain the crisp possibilistic semi-absolute deviation of the return associated with the portfolio $P(x)=\left(x_{1}, x_{2}, \ldots, x_{n}\right)$ as follows:

$$
\begin{aligned}
\bar{\omega}(P) & =\frac{P_{u}(x)-P_{l}(x)}{2}+\frac{C(x)+D(x)}{6} \\
& =\frac{1}{2} \sum_{j=1}^{n}\left(b_{j}-a_{j}+\frac{1}{3}\left(\alpha_{j}+\beta_{j}\right)\right) x_{j} .
\end{aligned}
$$

Moreover, the possibilistic mean value of the return associated with the portfolio $P(x)=\left(x_{1}, x_{2}, \ldots, x_{n}\right)$ is given by

$$
\begin{aligned}
\bar{M}(P) & =\frac{1}{2}\left(P_{l}(x)+P_{u}(x)\right)-\frac{1}{6}(C(x)-D(x)) \\
& =\sum_{j=1}^{n} \frac{1}{2}\left(a_{j}+b_{j}+\frac{\beta_{j}-\alpha_{j}}{3}\right) x_{j} .
\end{aligned}
$$

Analogous to Markowitz's mean-variance methodology for the portfolio selection problem, the crisp possibilistic mean value corresponds to the return while the possibilistic semi-absolute deviation corresponds to the risk. Starting from this point of view, the possibilistic portfolio model with different interest rates for borrowing and lending can be formulated as

$$
\begin{array}{ll}
\min & \frac{1}{2} \sum_{j=1}^{n}\left[b_{j}-a_{j}+\frac{1}{3}\left(\alpha_{j}+\beta_{j}\right)\right] x_{j} \\
\text { s.t. } & \sum_{j=1}^{n} \frac{1}{2}\left[a_{j}+b_{j}+\frac{1}{3}\left(\beta_{j}-\alpha_{j}\right)\right] x_{j}+\left(1-\sum_{j=1}^{n} x_{j}\right) r(x) \geq \mu, \\
& 0 \leq x_{j} \leq u_{j}, \quad j=1,2, \ldots, n .
\end{array}
$$

The possibilistic portfolio model (2.17) is based on possibility distributions rather than probability distributions. In conventional mean-variance methodology for portfolio selection, 
$r_{j}$ is regarded as a random variable, $j=1,2, \ldots, n$. It should be noted that the meanvariance model of portfolio selection based on probability theory usually contains $\left(n^{2}+3 n\right) / 2$ unknown parameters, including $n$ expected returns, $n$ variances, and $\left(n^{2}-n\right) / 2$ covariances. But the model (2.17) only contains $4 n$ unknown parameters including $a_{j}, b_{j}, \alpha_{j}, \beta_{j}, j=$ $1,2, \ldots, n$. Clearly, compared with conventional probabilistic mean-variance methodology, the unknown parameters in the model (2.17) are greatly decreased.

The problem (2.17) can be solved by the following two linear programming problems:

$$
\begin{array}{ll}
\min & \frac{1}{2} \sum_{j=1}^{n}\left[b_{j}-a_{j}+\frac{1}{3}\left(\alpha_{j}+\beta_{j}\right)\right] x_{j} \\
\text { s.t. } & \sum_{j=1}^{n} \frac{1}{2}\left[a_{j}+b_{j}+\frac{1}{3}\left(\beta_{j}-\alpha_{j}\right)\right] x_{j}+\left(1-\sum_{j=1}^{n} x_{j}\right) r_{l} \geq \mu, \\
& 1-\sum_{j=1}^{n} x_{j}<0, \quad j=1,2, \ldots, n, \\
& 0 \leq x_{j} \leq u_{j}, \quad j=1,2, \ldots, n, \\
\min & \frac{1}{2} \sum_{j=1}^{n}\left[b_{j}-a_{j}+\frac{1}{3}\left(\alpha_{j}+\beta_{j}\right)\right] x_{j} \\
\text { s.t. } & \sum_{j=1}^{n} \frac{1}{2}\left[a_{j}+b_{j}+\frac{1}{3}\left(\beta_{j}-\alpha_{j}\right)\right] x_{j}+\left(1-\sum_{j=1}^{n} x_{j}\right) r_{b} \geq \mu, \\
& 1-\sum_{j=1}^{n} x_{j}<0, \quad j=1,2, \ldots, n, \\
& 0 \leq x_{j} \leq u_{j}, \quad j=1,2, \ldots, n .
\end{array}
$$

Of the solutions to the two linear programs, the one with smaller risk is the solution to the programming problem (2.17). It should be noted that if only lending is allowed, the model (2.18) is used to obtain the optimal portfolio. On the other hand, if only borrowing is allowed, the model (2.19) is used to obtain the optimal portfolio. It is obvious that the model (2.17) is extension of previous models for portfolio selection problem, such as the models in $[1,22,36]$.

Furthermore, the problem (2.17) can be simplified to some special forms of possibility distributions.

For $j=1,2, \ldots, n$, if $\alpha_{j}=\beta_{j}$, that is, $r_{j}=\left(a_{j}, b_{j}, \alpha_{j}\right)$ is a symmetric trapezoidal fuzzy number, then the model (2.17) is equal to the following programming problem:

$$
\begin{array}{ll}
\min & \frac{1}{2} \sum_{j=1}^{n}\left(b_{j}-a_{j}+\frac{2}{3} \alpha_{j}\right) x_{j} \\
\text { s.t. } & \frac{1}{2} \sum_{j=1}^{n}\left(a_{j}+b_{j}\right) x_{j}+\left(1-\sum_{j=1}^{n} x_{j}\right) r(x) \geq \mu, \\
& 0 \leq x_{j} \leq u_{j}, \quad j=1,2, \ldots, n .
\end{array}
$$


Especially, if $\alpha_{j}=\beta_{j}=0$, that is, $r_{j}=\left[a_{j}, b_{j}\right]$ is an interval fuzzy number, then the problem (2.17) can be simplified as

$$
\begin{array}{ll}
\min & \frac{1}{2} \sum_{j=1}^{n}\left(b_{j}-a_{j}\right) x_{j} \\
\text { s.t. } & \frac{1}{2} \sum_{j=1}^{n}\left(a_{j}+b_{j}\right) x_{j}+\left(1-\sum_{j=1}^{n} x_{j}\right) r(x) \geq \mu, \\
& 0 \leq x_{j} \leq u_{j}, \quad j=1,2, \ldots, n .
\end{array}
$$

If $a_{j}=b_{j}$, that is, $r_{j}=\left(a_{j}, \alpha_{j}, \beta_{j}\right)$ is a triangular fuzzy number with center $a_{j}$, left-width $\alpha_{j}>0$ and right-width $\beta_{j}>0$, then the model (2.17) is equal to the following programming problem:

$$
\begin{array}{ll}
\min & \frac{1}{6} \sum_{j=1}^{n}\left(\alpha_{j}+\beta_{j}\right) x_{j} \\
\text { s.t. } & \sum_{j=1}^{n}\left[a_{j}+\frac{1}{6}\left(\beta_{j}-\alpha_{j}\right)\right] x_{j}+\left(1-\sum_{j=1}^{n} x_{j}\right) r(x) \geq \mu, \\
& 0 \leq x_{j} \leq u_{j}, \quad j=1,2, \ldots, n .
\end{array}
$$

\section{Numerical Example}

In order to illustrate our proposed effective approaches for the portfolio selection problem in this paper, we give a numerical example introduced by Markowitz in 1959 [3]. Since we assume the return of asset $j$ is a trapezoidal fuzzy number with the tolerance interval $\left[a_{j}, b_{j}\right]$, left width $\alpha_{j}$ and right width $\beta_{j}$, we need to estimate these parameters. Up to now, several methods have been proposed to estimate trapezoidal fuzzy returns such as possibilistic regression [40] sample percentile [22]. In the following, we will introduce the sample percentile method used by Vercher et al. [22] to approximate the core and spreads of the trapezoidal fuzzy returns for the Markowitz's historical dataset. Firstly, based on the Markowitz's historical data, the percentiles of returns are calculated, which are shown in Table 1 . Secondly, set the interval $\left[P_{40}, P_{60}\right]$ as the core $\left[a_{j}, b_{j}\right]$, the quantities $P_{40}-P_{5}$ and $P_{95}-P_{60}$ as the left $\alpha_{j}$ and right $\beta_{j}$ spreads, respectively, where $P_{k}$ is the $k$ th percentile of the sample. Thus, the possibility distribution of asset $j$ is obtained, that is, $a_{j}=P_{40}, b_{j}=P_{60}$, $\alpha_{j}=P_{40}-P_{5}, \beta_{j}=P_{95}-P_{60}$. Taking the stock 1 as an example, we will introduce the above method. From Table 1, we can see that for the stock $1, P_{5}=-0.284, P_{40}=-0.011, P_{60}=0.070$, $P_{95}=0.456$. Thus, we obtain the possibility distribution of stock 1 , that is, $a_{1}=P_{40}=-0.011$, $b_{1}=P_{60}=0.070, \alpha_{1}=P_{40}-P_{5}=0.273$, and $\beta_{1}=P_{95}-P_{60}=0.386$. Similarly, we can get the possibilistic distributions of other eight stocks. The possibilistic distributions of nine stocks are shown in Table 2.

We assume that the interest rate of borrowing is $4 \%$, the interest rate of lending is $1 \%$, and the upper bounds for nine assets are 0.25. By solving models (2.18) and (2.19), 
Table 1: Sample statistics for the Markowitz's historical data.

\begin{tabular}{lcccccc}
\hline Stock & Sample mean & SD & 5th percentile & 40th percentile & 60th percentile & 95th percentile \\
\hline 1 & 0.066 & 0.238 & -0.284 & -0.011 & 0.070 & 0.456 \\
2 & 0.062 & 0.125 & -0.175 & 0.052 & 0.089 & 0.229 \\
3 & 0.146 & 0.301 & -0.193 & 0.018 & 0.136 & 0.758 \\
4 & 0.173 & 0.318 & -0.307 & 0.161 & 0.238 & 0.714 \\
5 & 0.198 & 0.368 & -0.429 & 0.062 & 0.325 & 0.671 \\
6 & 0.055 & 0.209 & -0.234 & -0.064 & 0.094 & 0.352 \\
7 & 0.128 & 0.175 & -0.132 & 0.090 & 0.164 & 0.356 \\
8 & 0.118 & 0.286 & -0.311 & 0.104 & 0.196 & 0.587 \\
9 & 0.116 & 0.290 & -0.316 & 0.104 & 0.196 & 0.587 \\
\hline
\end{tabular}

Table 2: Possibility distributions of returns.

\begin{tabular}{lcccc}
\hline Stock & $a_{i}$ & $b_{i}$ & $\alpha_{i}$ & $\beta_{i}$ \\
\hline 1 & -0.011 & 0.070 & 0.273 & 0.386 \\
2 & 0.052 & 0.089 & 0.227 & 0.140 \\
3 & 0.018 & 0.136 & 0.211 & 0.622 \\
4 & 0.161 & 0.238 & 0.468 & 0.476 \\
5 & 0.062 & 0.325 & 0.491 & 0.346 \\
6 & -0.064 & 0.094 & 0.170 & 0.258 \\
7 & 0.090 & 0.164 & 0.222 & 0.192 \\
8 & 0.104 & 0.196 & 0.415 & 0.391 \\
9 & 0.104 & 0.196 & 0.420 & 0.391 \\
\hline
\end{tabular}

respectively, we can obtain the optimal investment strategies for different required return levels as shown in Table 3. All efficient portfolios do not contain security 3 , that is, $x_{3}=0$. If the investor is not satisfied with any of the portfolios obtained, more portfolios can be obtained by varying the value of $\mu$.

From Table 3 we can see that when borrowing and lending are allowed, the investor can make different portfolio decisions to obtain the same expected returns. For example, for $\mu=8 \%$, one investing strategy is that the investor holds $22 \%$ security $4,25 \%$ security 7 , and $53 \%$ risk-free asset by lending, while another is that the investor only holds some risky assets without borrowing and lending risk-free asset, that is, $25 \%$ security $1,25 \%$ security $2,11.24 \%$ security $6,25 \%$ security 7 , and $13.76 \%$ security 8 . Furthermore, which strategies are better for the investor if borrowing and lending are allowed? It is obvious that the investor will choose the portfolio based on the model (2.18) because its risk is lower than that based on the model (2.19). That is to say, the better portfolio decision can be made by lending. Moreover, when expected return $\mu=16.5 \%$, even if borrowing and lending are allowed, the investor will invest total capital in risky assets and stand $19.25 \%$ risk.

Next, in order to illustrate that borrowing and lending have effect on the optimal portfolio selection, we consider two cases, that is, portfolio selection without borrowing and 
Table 3: Some possibilistic efficient portfolios.

\begin{tabular}{lcccccccc}
\hline & \multicolumn{2}{c}{$\mu=0.03$} & \multicolumn{2}{c}{$\mu=0.08$} & \multicolumn{2}{c}{$\mu=0.13$} & \multicolumn{2}{c}{$\mu=0.165$} \\
& $\mathbf{P}(4)$ & $\mathbf{P}(5)$ & $\mathbf{P}(4)$ & $\mathbf{P}(5)$ & $\mathbf{P}(4)$ & $\mathbf{P}(5)$ & $\mathbf{P}(4)$ & $\mathbf{P}(5)$ \\
\hline$x_{1}$ & 0 & 0.25 & 0 & 0.25 & 0 & 0.0123 & 0 & 0 \\
$x_{2}$ & 0 & 0.25 & 0 & 0.25 & 0 & 0.25 & 0 & 0 \\
$x_{3}$ & 0 & 0 & 0 & 0 & 0 & 0 & 0 & 0 \\
$x_{4}$ & 0 & 0 & 0.22 & 0 & 0.25 & 0.25 & 0.25 & 0.25 \\
$x_{5}$ & 0 & 0 & 0 & 0 & 0 & 0 & 0.25 & 0.25 \\
$x_{6}$ & 0 & 0.25 & 0 & 0.1124 & 0 & 0 & 0 & 0 \\
$x_{7}$ & 0.1786 & 0.25 & 0.25 & 0.25 & 0.25 & 0.25 & 0.014 & 0.014 \\
$x_{8}$ & 0 & 0 & 0 & 0.1376 & 0.25 & 0.2377 & 0.25 & 0.25 \\
$x_{9}$ & 0 & 0 & 0 & 0 & 0.076 & 0 & 0.236 & 0.236 \\
$1-\sum_{j=1}^{9} x_{j}$ & 0.8214 & 0 & 0.53 & 0 & 0.174 & 0 & 0 & 0 \\
Risk & 0.1893 & 0.1216 & 0.0696 & 0.1257 & 0.134 & 0.14 & 0.1925 & 0.1925 \\
\hline
\end{tabular}

Table 4: Optimal solutions of two models $(\mu=0.05)$.

\begin{tabular}{lccccccccccc}
\hline & $x_{1}$ & $x_{2}$ & $x_{3}$ & $x_{4}$ & $x_{5}$ & $x_{6}$ & $x_{7}$ & $x_{8}$ & $x_{9}$ & $1-\sum_{j=1}^{9} x_{j}$ & Risk \\
\hline Model (2.17) & 0 & 0 & 0 & 0.0629 & 0 & 0 & 0.25 & 0 & 0 & 0.6871 & 0.0388 \\
Model (3.1) & 0.25 & 0.25 & 0 & 0 & 0 & 0.25 & 0.25 & 0 & 0 & 0 & 0.1216 \\
\hline
\end{tabular}

lending and portfolio selection with borrowing and lending. Based on the model (2.17), we easily obtain the portfolio selection model without borrowing and lending as follows:

$$
\begin{array}{ll}
\min & \frac{1}{2} \sum_{j=1}^{n}\left[b_{j}-a_{j}+\frac{1}{3}\left(\alpha_{j}+\beta_{j}\right)\right] x_{j} \\
\text { s.t. } & \sum_{j=1}^{n} \frac{1}{2}\left[a_{j}+b_{j}+\frac{1}{3}\left(\beta_{j}-\alpha_{j}\right)\right] x_{j} \geq \mu, \\
& 0 \leq x_{j} \leq u_{j}, \quad j=1,2, \ldots, n .
\end{array}
$$

Assume that $\mu=0.05,0.12$, we obtained some possibilistic efficient portfolios, which are shown in Tables 4 and 5, respectively. It should be noted that the interest rates of borrowing and lending, and the upper bounds for nine assets are the same with the above assumptions.

From Tables 4 and 5, it can be seen that whether the borrowing and lending are considered, when the preset return value becomes bigger, the risk becomes larger, which reflects the relationship between risk and return. For example, if borrowing and lending are considered, when possibilistic return $\mu=0.05$, the risk is 0.0388 , while when possibilistic return $\mu=0.12$, the risk is 0.1209 . Moreover, by comparing models (2.17) and (3.1), we can see that, whether $\mu=0.05$ or $\mu=0.12$, the investment risk for the model (2.17) is lower than that for the model (3.1). That is to say, borrowing and lending constraints have great effect on making the optimal strategies.

In particular, to demonstrate that different borrowing and lending interest rates also have effect on the optimal portfolio selection, we consider two special cases: (a) only lending 
Table 5: Optimal solutions of two models $(\mu=0.12)$.

\begin{tabular}{lccccccccccc}
\hline & $x_{1}$ & $x_{2}$ & $x_{3}$ & $x_{4}$ & $x_{5}$ & $x_{6}$ & $x_{7}$ & $x_{8}$ & $x_{9}$ & $1-\sum_{j=1}^{9} x_{j}$ & Risk \\
\hline Model (2.17) & 0 & 0 & 0 & 0.25 & 0 & 0 & 0.25 & 0.25 & 0.0022 & 0.2478 & 0.1209 \\
Model (3.1) & 0.1146 & 0.25 & 0 & 0.25 & 0 & 0 & 0.25 & 0.1354 & 0 & 0 & 0.1370 \\
\hline
\end{tabular}

Table 6: Some possibilistic efficient portfolios with different lending interest rates $(\mu=10 \%)$.

\begin{tabular}{lccccccc}
\hline$r_{l}$ & 0 & 0.02 & 0.03 & 0.05 & 0.07 & 0.09 & 0.10 \\
\hline$x_{1}$ & 0 & 0 & 0 & 0 & 0 & 0 & 0 \\
$x_{2}$ & 0 & 0 & 0 & 0 & 0 & 0 & 0 \\
$x_{3}$ & 0 & 0 & 0 & 0 & 0 & 0 & 0 \\
$x_{4}$ & 0 & 0 & 0.4098 & 0.3316 & 0.2294 & 0.0903 & 0 \\
$x_{5}$ & 0 & 0 & 0 & 0 & 0 & 0 & 0 \\
$x_{6}$ & 0 & 0 & 0 & 0 & 0 & 0 & 0 \\
$x_{7}$ & 0.8197 & 0.7844 & 0 & 0 & 0 & 0 & 0 \\
$x_{8}$ & 0 & 0 & 0 & 0 & 0 & 0 & 0 \\
$x_{9}$ & 0 & 0 & 0 & 0 & 0 & 0 & 0 \\
$1-\sum_{j=1}^{9} x_{j}$ & 0.1803 & 0.2156 & 0.5902 & 0.6684 & 0.7706 & 0.9097 & 1 \\
Risk & 0.0869 & 0.0831 & 0.0802 & 0.0649 & 0.0449 & 0.0177 & 0 \\
\hline
\end{tabular}

is allowed for portfolio selection, (b) only borrowing is allowed for portfolio selection. That is to say, models (2.18) and (2.19) are considered independently for portfolio selection problem. For simplicity, we assume $u_{j}=1, j=1,2, \ldots, 9$. With respect to each case, we solve these problems with different borrowing and lending interest rates and obtain optimal portfolios as shown in Tables 6 and 7.

Table 6, representing the possibilistic efficient portfolios under assumption that lending is allowed, shows that with the lending interest rate increases, the proportion invested in risk-free asset becomes bigger. Especially, if $r_{l} \geq 0.10$, the investor will invest total capital in the risk-free asset. This implies that when $r_{l}$ is greater than or equal to the expected returns $\mu$, the investor makes his portfolio selection pessimistically. Consequently, the investor prefers to hold risk-free asset than part or whole risky assets. Table 7, representing the possibilistic efficient portfolios under assumption that borrowing is allowed, shows that the larger the borrowing interest rate is, the larger the possibilistic risk of portfolio is. It must be emphasized that an increase on the borrowing interest rate $r_{b}$ does not necessarily result in an increase on the borrowing amount. For example, when $r_{b}=0.05$, the proportions of borrowing is 0.6833 while when $r_{b}=0.02$, the proportions of borrowing is 0.708 . Moreover, in order to find feasible solution the borrowing interest rate $r_{b}$ must be less than or equal to $14 \%$.

Finally, we depict a graph, as shown in Figure 1, to show the difference of the possibilistic efficient frontiers under different cases. The vertical axis is the possibilistic return value of the portfolio, and the horizontal axis is the possibilistic risk value of the portfolio. Figure 1(a) presents the efficient frontiers without borrowing and lending, with borrowing and lending, and only with borrowing. Generally speaking, the efficient frontier without borrowing and lending is lower than that with borrowing and lending, and the efficient frontier only with borrowing partly covers that without borrowing and lending. Figure 1(b) presents the efficient frontiers without borrowing and lending, with borrowing and lending, 
Table 7: Some possibilistic efficient portfolios with different borrowing interest rates $(\mu=25 \%)$.

\begin{tabular}{lccccccc}
\hline$r_{b}$ & 0 & 0.02 & 0.05 & 0.10 & 0.11 & 0.12 & 0.139 \\
\hline$x_{1}$ & 0 & 0 & 0 & 0 & 0 & 0 & 0 \\
$x_{2}$ & 0 & 0 & 0 & 0 & 0 & 0 & 0 \\
$x_{3}$ & 0 & 0 & 0 & 0 & 0 & 0 & 0.8769 \\
$x_{4}$ & 0.6375 & 0.708 & 1 & 1 & 1 & 1 & 1 \\
$x_{5}$ & 0 & 0 & 0 & 0.71 & 0.8297 & 0.998 & 1 \\
$x_{6}$ & 0 & 0 & 0 & 0 & 0 & 0 & 0 \\
$x_{7}$ & 1 & 1 & 0.6833 & 0 & 0 & 0 & 0 \\
$x_{8}$ & 0 & 0 & 0 & 0 & 0 & 0 & 1 \\
$x_{9}$ & 0 & 0 & 0 & 0 & 0 & 0 & 1 \\
$\sum_{j=1}^{9} x_{j}-1$ & 0.6375 & 0.708 & 0.6833 & 0.71 & 0.8297 & 0.998 & 3.8769 \\
Risk & 0.2308 & 0.2446 & 0.2682 & 0.3499 & 0.3758 & 0.4124 & 0.948 \\
\hline
\end{tabular}

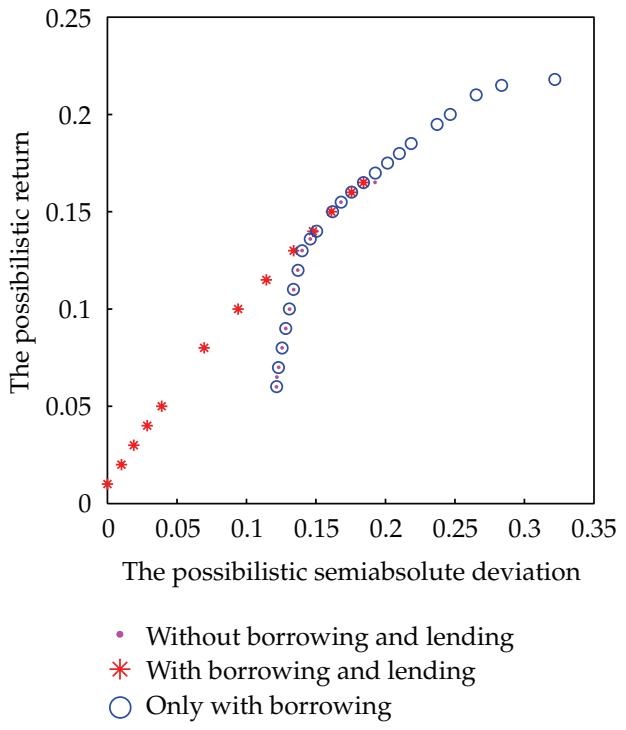

(a)

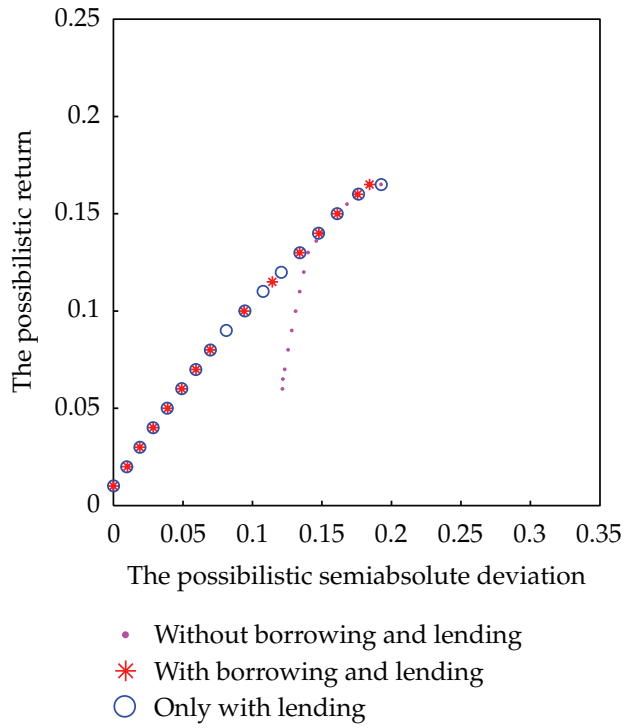

(b)

Figure 1: A comparison of possibilistic efficient frontiers under different cases.

and only with lending. We find that the efficient frontier without borrowing and lending is lower than that with borrowing and lending, and that only with borrowing. Moreover, theoretically, the efficient frontier with borrowing and lending should be different from that only with lending. However, in our example, we can see that these two curves are completely the same. The main reasons are that borrowing has little influence on portfolio selection by using Markowitz's historical data. Finally, comparing Figure 1(a) with Figure 1(b), it is easy to see that, whatever the case, the investor will make the same investment decisions when expected return $\mu$ varies within a certain range such as $\mu \in[0.145,0.165]$. It must be emphasized that in order to find the feasible solutions, the expected return must satisfy $\mu \leq 0.218$ for the case that only borrowing is allowed, and $\mu \leq 0.165$ for the other three cases. 


\section{Conclusion}

The fuzzy set is one of the powerful tools used to describe a uncertain environment. In this paper, we have discussed the portfolio selection problem based on the possibilistic theory under the assumption that the returns of assets are trapezoidal fuzzy numbers. We have used possibilistic mean value of the return to measure the investment return, and possibilistic semi-absolute deviation as the investment risk. We have obtained a new possibilistic mean semi-absolute deviation model for portfolio selection taking into account of different interest rates for borrowing and lending. Comparing with conventional probabilistic mean-variance model, our proposed model contains less unknown parameters and it can integrate the experts' knowledge and the managers' subjective opinions better. Numerical results have showed that our proposed model is efficient and borrowing and lending risk-free asset have great effect on the optimal portfolio selection.

Finally, for future researches, three areas are proposed: first adding other constraints of real market such as transaction costs, cardinality, and bounded constraint, second using heuristic algorithms such as artificial bee colony $(\mathrm{ABC})$ algorithm to solve the proposed model and comparing its solutions with GA and PSO, and lastly, extending the proposed model to a multiperiod case.

\section{Acknowledgments}

This paper was supported by the Funding Project for Academic Human Resources Development in Institutions of Higher Learning under the Jurisdiction of Beijing Municipality (no. PHR201007117, PHR201108333), the Beijing Municipal Education Commission Foundation of China (no. KM201010038001, KM201110038002), the key Project of Capital University of Economics and Business (no. 2011SJZ015), the Funding Project of Scientific Research Department in the Capital University of Economics and Business.

\section{References}

[1] H. Markowitz, "Portfolio selection," Journal of Finance, vol. 7, pp. 77-91, 1952.

[2] A. D. Roy, "Safety-first and the holding of assets," Econometrica, vol. 20, pp. 431-449, 1952.

[3] H. M. Markowitz, Portfolio Selection: Efficient Diversification of Investments, John Wiley \& Sons, New York, NY, USA, 1959.

[4] H. Konno and H. Yamazaki, "Mean-absolute deviation portfolio optimization model and its applications to Tokyo stock market," Management Science, vol. 37, pp. 519-531, 1991.

[5] M. G. Speranza, "Linear programming models for portfolio optimization," Finance, vol. 12, pp. 107123, 1993.

[6] M. R. Young, "A minimax portfolio selection rule with linear programming solution," Management Science, vol. 44, no. 5, pp. 673-683, 1998.

[7] G. J. Alexander and A. M. Baptista, "Value at risk and mean-variance analysis," Working paper, University of Minnesota, 1999.

[8] G. J. Alexander and A. M. Baptista, "Economic implications of using a mean-VaR model for portfolio selection: a comparison with mean-variance analysis," Journal of Economic Dynamics \& Control, vol. 26, no. 7-8, pp. 1159-1193, 2002.

[9] R. T. Rockafellar and S. Uryasev, "Optimization of conditional value-at-risk," Journal of Risk, vol. 2, pp. 21-41, 2000.

[10] S. Alexander, T. F. Coleman, and Y. Li, "Minimizing CVaR and VaR for a portfolio of derivatives," Journal of Banking \& Finance, vol. 30, pp. 583-605, 2006.

[11] S. Ciliberti, I. Kondor, and M. Mézard, "On the feasibility of portfolio optimization under expected shortfall," Quantitative Finance, vol. 7, no. 4, pp. 389-396, 2007.

[12] L. A. Zadeh, "Fuzzy sets," Information and Computation, vol. 8, pp. 338-353, 1965. 
[13] J. Watada, "Fuzzy portfolio selection and its applications to decision making," Tatra Mountains Mathematical Publications, vol. 13, pp. 219-248, 1997.

[14] H. Tanaka and P. Guo, "Portfolio selection based on upper and lower exponential possibility distributions," European Journal of Operational Research, vol. 114, no. 1, pp. 115-126, 1999.

[15] M. Inuiguchi and J. Ramík, "Possibilistic linear programming: a brief review of fuzzy mathematical programming and a comparison with stochastic programming in portfolio selection problem," Fuzzy Sets and Systems, vol. 111, no. 1, pp. 3-28, 2000.

[16] H. Tanaka, P. Guo, and I. B. Türksen, "Portfolio selection based on fuzzy probabilities and possibility distributions," Fuzzy Sets and Systems, vol. 111, no. 3, pp. 387-397, 2000.

[17] M. Inuiguchi and T. Tanino, "Portfolio selection under independent possibilistic information," Fuzzy Sets and Systems, vol. 115, no. 1, pp. 83-92, 2000.

[18] M. Arenas Parra, A. Bilbao Terol, and M. V. Rodríguez Uría, "A fuzzy goal programming approach to portfolio selection," European Journal of Operational Research, vol. 133, no. 2, pp. 287-297, 2001.

[19] C. Carlsson, R. Fullér, and P. Majlender, "A possibilistic approach to selecting portfolios with highest utility score," Fuzzy Sets and Systems, vol. 131, no. 1, pp. 13-21, 2002.

[20] Y. Fang, K. K. Lai, and S. Y. Wang, "Portfolio rebalancing model with transaction costs based on fuzzy decision theory," European Journal of Operational Research, vol. 175, no. 2, pp. 879-893, 2006.

[21] A. Bilbao-Terol, B. Pérez-Gladish, M. Arenas-Parra, and M. V. Rodríguez-Uría, "Fuzzy compromise programming for portfolio selection," Applied Mathematics and Computation, vol. 173, no. 1, pp. 251$264,2006$.

[22] E. Vercher, J. D. Bermúdez, and J. V. Segura, "Fuzzy portfolio optimization under downside risk measures," Fuzzy Sets and Systems, vol. 158, no. 7, pp. 769-782, 2007.

[23] W.-G. Zhang, Y.-L. Wang, Z.-P. Chen, and Z.-K. Nie, "Possibilistic mean-variance models and efficient frontiers for portfolio selection problem," Information Sciences, vol. 177, no. 13, pp. 2787-2801, 2007.

[24] E. E. Ammar, "On solutions of fuzzy random multiobjective quadratic programming with applications in portfolio problem," Information Sciences, vol. 178, no. 2, pp. 468-484, 2008.

[25] P. Gupta, K. M. Mukesh, and S. Anand, "Asset portfolio optimization using fuzzy mathematical programming," Information Sciences, vol. 178, no. 6, pp. 1734-1755, 2008.

[26] W. Chen, "Weighted portfolio selection models based on possibility theory," Fuzzy Information and Engineering, vol. 1, pp. 115-127, 2009.

[27] L. H. Chen and L. Huang, "Portfolio optimization of equity mutual funds with fuzzy return rates and risks," Expert Systems with Applications, vol. 36, no. 2, pp. 3720-3727, 2009.

[28] X. Li, Z. Qin, and S. Kar, "Mean-variance-skewness model for portfolio selection with fuzzy returns," European Journal of Operational Research, vol. 202, no. 1, pp. 239-247, 2010.

[29] W. Chen and W. G. Zhang, "The admissible portfolio selection problem with transaction costs and an improved PSO algorithm," Physica A, vol. 389, no. 10, pp. 2070-2076, 2010.

[30] W. G. Zhang, W. L. Xiao, and W. J. Xu, "A possibilistic portfolio adjusting model with new added assets," Economic Modelling, vol. 27, no. 1, pp. 208-213, 2010.

[31] R. Bhattacharyya, S. Kar, and D. D. Majumder, "Fuzzy mean-variance-skewness portfolio selection models by interval analysis," Computers $\mathcal{E}$ Mathematics with Applications, vol. 61, no. 1, pp. 126-137, 2011.

[32] J. Tobin, "Liquidity preferences as behaviour towards," Review of Economics Studies, vol. 25, pp. 65-86, 1958.

[33] M. J. Brennan, "Capital market equilibrium with divergent borrowing and lending rates," Journal of Financial and Quantitative Analysis, vol. 6, pp. 1197-1205, 1971.

[34] D. J. Bradfield and H. Raubenheimer, "A note on portfolio selection with restrictions on leverage," European Journal of Operational Research, vol. 134, no. 2, pp. 243-248, 2001.

[35] S. Zhang, S. Wang, and X. Deng, "Portfolio selection theory with different interest rates for borrowing and lending," Journal of Global Optimization, vol. 28, no. 1, pp. 67-95, 2004.

[36] W.-G. Zhang and Y.-L. Wang, "An analytic derivation of admissible efficient frontier with borrowing," European Journal of Operational Research, vol. 184, no. 1, pp. 229-243, 2008.

[37] D. Olson and J. Bley, "Asset allocation with differential borrowing and lending rates," International Review of Economics and Finance, vol. 17, no. 4, pp. 629-643, 2008.

[38] B. Liu, Uncertainty Theory, Springer, Berlin, Germany, 2nd edition, 2007.

[39] C. Carlsson and R. Fullér, “On possibilistic mean value and variance of fuzzy numbers," Fuzzy Sets and Systems, vol. 122, no. 2, pp. 315-326, 2001.

[40] J.-J. Huang, G.-H. Tzeng, and C.-S. Ong, "A novel algorithm for uncertain portfolio selection," Applied Mathematics and Computation, vol. 173, no. 1, pp. 350-359, 2006. 


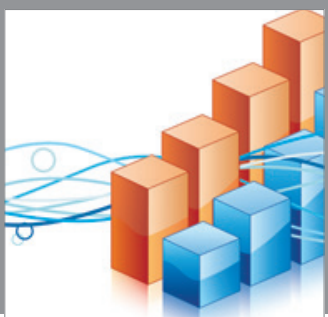

Advances in

Operations Research

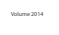

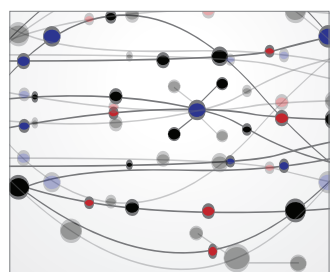

\section{The Scientific} World Journal
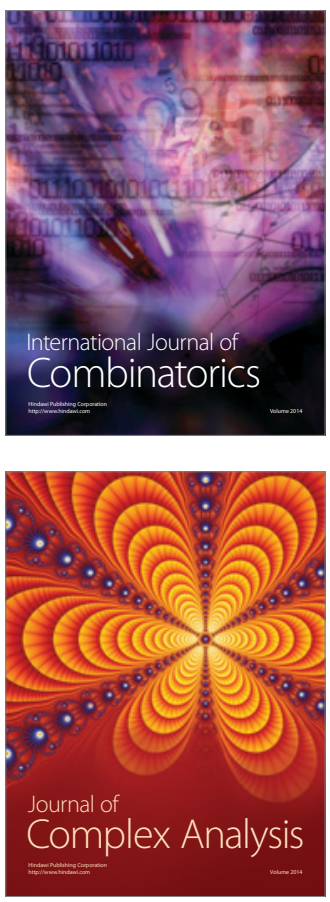

International Journal of

Mathematics and

Mathematical

Sciences
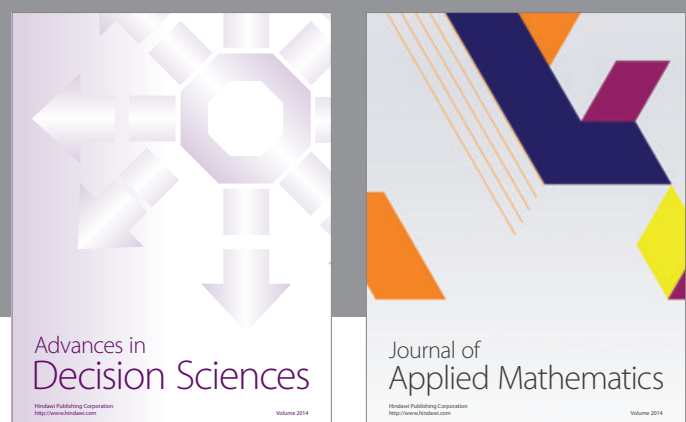

Journal of

Applied Mathematics
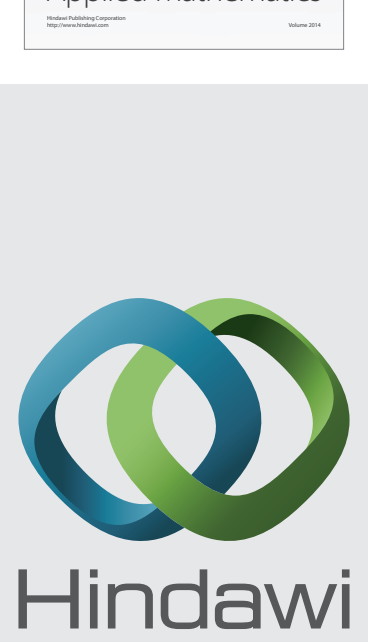

Submit your manuscripts at http://www.hindawi.com
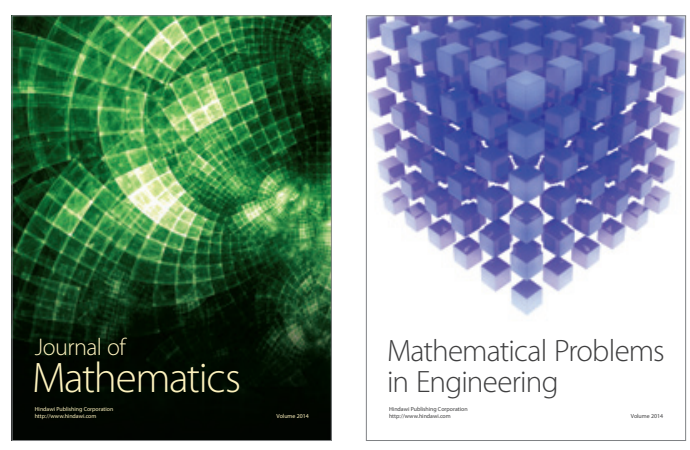

Mathematical Problems in Engineering
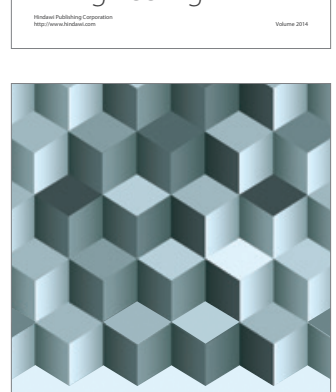

Journal of

Function Spaces
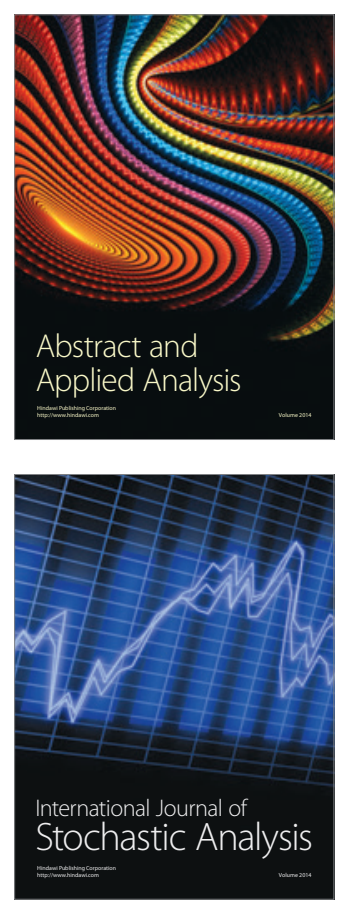

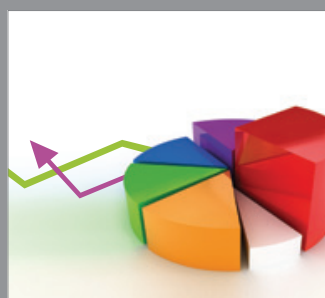

ournal of

Probability and Statistics

Promensencen
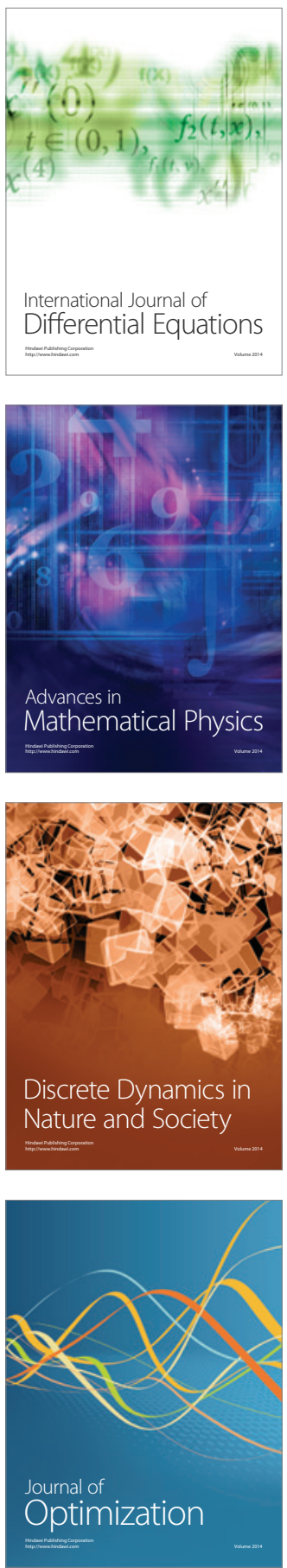